\title{
Consumo Alimentar e Crescimento do Predador Supputius cincticeps (Stäl) (Heteroptera:Pentatomidae) Alimentando-se de Lagartas de Curuquerê-do-Algodoeiro
}

\author{
Evandro N. Silva ${ }^{1}$, Terezinha M. Santos ${ }^{1}$ e Francisco S. Ramalho ${ }^{1,2}$ \\ ${ }^{1}$ Unidade de Controle Biológico, CNPA/EMBRAPA/UFPB, Caixa postal, \\ 174, 58107-720, Campina Grande, PB. \\ ${ }^{2}$ Autor correspondente.
}

An. Soc. Entomol. Brasil 26(2): 349-357 (1997)

Food Consumption and Growth of the Predator Supputius cincticeps

(Stäl)(Heteroptera:Pentatomidae) Fed Larvae of Cotton Leafworm

\begin{abstract}
The amount of food consumed by nymphs of Supputius cincticeps (Stäl) and the relationship between food intake and growth and development rates using larvae of cotton leafworm Alabama argillacea (Huebner) as food was evaluated. The regression analysis indicated a quadratic function between daily growth of 2 nd-instar nymphs of $S$. cincticeps and food consumption, but for the 3 rd - 5th instars this function was linear. Nymphs fed with small preys $(4.71 \mathrm{mg})$ had their growth reduced $(75.3 \%)$. The rate of development showed a linear relationship with the daily food consumption for each instar of the predator. For the 4th and 5th instars, the period of development increased (418.4 e $196.7 \%$, respectively) when small preys were supplied to the predator. The amount of food consumed in function of its availability, influenced the rates of growth and development, and the nymphal survival of $S$. cincticeps.
\end{abstract}

KEY WORDS: Insecta, stinkbug, predator, behavior, nutrition, Alabama argillacea.

RESUMO - Determinou-se a quantidade de alimento consumido por ninfas de Supputius cincticeps (Stäl) em relação à quantidade disponível de presa, e as relações entre o consumo de alimento pelas ninfas do predador e seu crescimento e desenvolvimento, tendo como alimento lagartas de $2^{\circ}, 3^{\circ}, 4^{\circ}$ e $5^{\circ}$ ínstares de Alabama argillacea (Huebner). Para o $2^{\circ}$ ínstar do predador, a regressão entre o crescimento diário de ninfas e o consumo de alimento foi quadrática e para os demais estádios foi linear. Ninfas que se alimentaram de presas pequenas $(4,71$ $\mathrm{mg}$ ), tiveram seu crescimento reduzido em $75,3 \%$. A taxa de desenvolvimento foi relacionada linearmente com o consumo diário de alimento, em cada um dos instares do predador. No $4^{\circ}$ e $5^{\circ}$ ínstares, o período de desenvolvimento foi prolongado em 418,4 e 196,7\%, respectivamente, quando as ninfas se alimentaram de presas pequenas. A quantidade de alimento consumido em função de sua maior ou menor disponibilidade, influenciou as taxas de crescimento e de desenvolvimento e a sobrevivência ninfal de $S$. cincticeps.

PALAVRAS-CHAVE: Insecta, Percevejo, predador, comportamento, nutrição, Alabama argillacea. 
Dentre as pragas do algodoeiro (Gossypium hirsutum raça latifolium), o curuquerê [(Alabama argillacea (Huebner)] é uma das mais importantes, em diversos países (Silva et al. 1996). As lagartas se alimentam das folhas e podem desfolhar completamente as plantas de algodão. Na região Nordeste do Brasil, o dano é mais acentuado na fase inicial da cultura, e na região Centro-Sul é durante o período de frutificação que se dá o maior ataque, causando sérios prejuízos na produção (Gravena \& Cunha 1991).

Para o controle da A. argillacea várias aplicações de produtos químicos são realizadas (Ramalho 1994). Essa prática pode causar efeitos indesejáveis aos agroecossistemas e aos agricultores que manuseiam esses produtos (Newsom \& Smith 1949). A utilização de percevejos predadores como agentes de controle biológico, pode ser uma alternativa contra A. argillacea. Entretanto, poucos são os resultados relacionados ao seu emprego contra essa praga no Brasil. A maioria dos trabalhos tem se detido no estudo de espécies dos gênero Podisus HerrichShafer (Grazia et al. 1985, Zanuncio et al. 1991, 1993a,b, Santos et al. 1995) e Supputius Distant (Zanuncio et al. 1993c, Silva et al. 1996)(Heteroptera: Pentatomidae: Asopinae). As pesquisas conduzidas no Brasil, não evidenciaram os componentes que estão envolvidos no desenvolvimento e consumo alimentar de pentatomídeos entomófagos. Assim, procurou-se determinar a quantidade de alimento que as ninfas do predador $S$. cincticeps podem consumir em relação a quantidade disponível de presa (lagartas de A. argillacea), e conhecer as relações entre o consumo de alimento pelas ninfas de $S$. cincticeps e seu crescimento e desenvolvimento, tendo como presas lagartas $d e 2^{\circ}$, $3^{\circ}, 4^{\circ}$ e $5^{\circ}$ ínstares de $A$. argillacea.

\section{Material e Métodos}

A pesquisa foi executada na Unidade de Controle Biológico (UCB) da Embrapa Algodão, Campina Grande, PB, de Fevereiro a Outubro de 1994, em câmara climatizada a $25^{\circ} \mathrm{C}$, UR $70 \pm 10 \%$ e fotofase de 12 horas. Foram utilizados espécimes do predador $S$. cincticeps e lagartas de A. argillacea, provenientes das colônias de criação da UCB. $\mathrm{Na}$ criação do predador, foram utilizadas como presa, larvas de Musca domestica L. em copos plásticos $(500 \mathrm{ml})$ e tubo de vidro (2 ml) contendo água destilada. As lagartas de curuquerê foram criadas em gaiolas de PVC $(20 \times 20 \mathrm{~cm})$ e alimentadas com folhas de algodoeiro herbáceo (cv. CNPA Precoce $1)$.

As ninfas do predador foram mantidas em placas de Petri $(90 \times 15 \mathrm{~mm})$ até atingirem o $2^{\circ}$ ínstar, quando foram individualizadas em potes plásticos $(100 \mathrm{ml})$. Ninfas de $2^{\circ}, 3^{\circ}, 4^{\circ} \mathrm{e}$ $5^{\circ}$ ínstares do predador foram alimentadas com lagartas de $2^{\circ}(4,7 \mathrm{mg}), 3^{\circ}(15,2 \mathrm{mg}), 4^{\circ}$ $(85,2 \mathrm{mg})$ e $5^{\circ}(197,7 \mathrm{mg})$ ínstares de $A$. argillacea, parcialmente imobilizadas.

No estudo do consumo alimentar do predador foi adotada a metodologia de Mukerji \& LeRoux (1969). Foram usadas 30 ninfas de $2^{\circ}$ instar do predador para cada tipo de alimento (lagartas de $2^{\circ}, 3^{\circ}, 4^{\circ}$ e $5^{\circ}$ ínstares de A. argillacea), totalizando 120 ninfas, as quais foram individualizadas em copos plásticos, oferecendo-se uma lagarta de curuquerê, a cada 24 horas.

Para determinar o consumo diário de alimento pelo predador, foi estimado diariamente o peso seco $(\mathrm{mg})$ da presa oferecida, em cada tipo de alimento. Para tanto, obteve-se o peso seco médio da presa, pesando-se diariamente 10 lagartas vivas de cada nível de alimento. Em seguida, as lagartas foram colocadas em envelopes de papel alumínio e secas em estufa, a $105^{\circ} \mathrm{C}$, por 4 horas. Os valores de peso seco obtidos diariamente, para cada nível de alimento, foram utilizados como estimativa do peso seco do alimento oferecido a cada espécime do predador, no início de um período de 24 horas.

O consumo diário de alimento (CDA) do predador, em cada tipo de alimento, foi obtido através da fórmula: $\mathrm{CDA}=\mathrm{PSe}-\mathrm{PSsa}$, onde PSe é o peso seco estimado do alimento oferecido ao predador no início de um período de 24 horas, e PSsa é o peso seco da sobra de 
alimento ao final de um período de 24 horas. O consumo diário médio de alimento (CDMa), para as ninfas de cada ínstar do predador foi calculado através da fórmula: $\mathrm{CDMa}=\mathrm{CTA} / \mathrm{N}$, onde CTA é o consumo total de alimento em cada ínstar, e $\mathrm{N}$ é o número de dias de alimentação em cada instar.

O crescimento do predador foi determinado em ganho de peso seco, subtraindo-se o peso seco médio inicial do peso seco médio final do corpo, em cada ínstar. Portanto, em cada nível de dieta, as três primeiras ninfas que mudavam de ínstar foram pesadas, individualmente, para se determinar o peso vivo, e levar a secagem em estufa a $105^{\circ} \mathrm{C}$, por quatro horas. Foram calculados, adotando-se o mesmo procedimento, os pesos vivos e secos das exúvias, os quais foram considerados como parte do peso final do corpo das ninfas no ínstar anterior à ecdise. $\mathrm{O}$ crescimento diário médio $(\mathrm{CrDm})$ do predador, nos quatro níveis de dieta, foi determinado usando-se a fórmula: $\mathrm{CrDm}=$ GP/N, onde GP é o ganho médio de peso seco no ínstar, e $\mathrm{N}$ é o número de dias gastos na alimentação, durante o ínstar.

O delineamento experimental utilizado foi inteiramente casualizado, com os tratamentos dispostos em esquema fatorial $4 \times 4$, representado pelos quatro alimentos e quatro ínstares do predador. As análises de variância foram realizadas pelo procedimento PROC GLM (SAS Institute 1993), e as médias comparadas pelo teste de Student-NewmanKeuls $(P=0,05)$. Foram conduzidas análises de regressão, usando-se crescimento diário e taxa de desenvolvimento do predador como variáveis dependentes, e consumo diário da presa pelo $S$. cincticeps como variável independente, adotando-se o procedimento PROC REG (SAS Institute 1993).

\section{Resultados e Dicussão}

As variáveis consumo diário e total de alimento, crescimento diário e período de desenvolvimento de ninfas de $S$. cincticeps variaram em função da quantidade de alimento disponível e do estádio de desenvolvimento do predador (Tabela 1). O consumo diário de alimento foi baixo, variando de 0,26 a $2.14 \mathrm{mg} / \mathrm{dia}$, em todos os ínstares, nas dietas onde a quantidade de alimento disponível foi menor (lagartas de $2^{\circ}$ e $3^{\circ}$ ínstares), aumentando de forma diretamente proporcional do $3^{\circ}$ ao $5^{\circ}$ ínstar, nas dietas onde a disponibilidade de alimento foi maior (lagartas de $4^{\circ}$ e $5^{\circ}$ ínstares) (Tabela 2). Além da qualidade da presa, a quantidade disponível e consumida de presas influenciam nas respostas do predador a presença da presa (Hagen 1987). Portanto, é provável que em condições de campo as taxas de busca e de ataque do $S$. cincticeps aumentem, devido ao baixo grau de "saciação", se a população da presa for constituída de lagartas de $1^{\text {os }}$ ínstares, e diminuem, em função do aumento do grau de "saciação" e também da capacidade de defesa da presa, se a população for constituída de lagartas dos últimos ínstares. Neste caso, algumas lagartas de curuquerê que se encontrarem nos últimos ínstares poderão sobreviver e reproduzir-se. Por outro lado, sabe-se que os predadores exercem um importante papel na manutenção da agressividade e vigor das presas, pois aquelas que não estiverem aptas a se defenderem serão eliminadas da população; aquelas com melhor aptidão para se defenderem ou de outra maneira, escaparem da predação, através da capacidade de aumentar o grau de saciação do predador e/ou de defesa, sobreviverão e se reproduzirão (Price 1975). Então, o predador atua como um agente seletivo na evolução de sua presa, selecionando os indivíduos mais fortes e vigorosos de cada geração, o que ao mesmo tempo causará a seleção de indivíduos de sua progênie que apresentarem técnicas de ataque mais eficazes, isto é, o predador e a presa coevoluem em busca da sua sobrevivência no agroecossistema.

Baseado nesta discussão, acredita-se que o comportamento de predação (ataque, "saciação" e pausa digestiva) de $S$. cincticeps e a presença de uma maior capacidade de defesa apresentada pelas lagartas de $A$. argillacea, nos últimos ínstares, poderão 
Tabena 1. Resumo das análises de variância para o consumo diário de alimento (CDA), consumo total de alimento (CTA), crescimento diário (CrD) e período médio de desenvolvimento (PMD) de ninfas de Supputius cincticeps.

\begin{tabular}{lccccc}
\hline Fonte de & Graus de & \multicolumn{4}{c}{ Quadrado Médio } \\
\cline { 3 - 6 } variação & liberdade & $\mathrm{CDA}^{1}$ & $\mathrm{CTA}^{1}$ & $\mathrm{CrD}^{1}$ & PMD $^{2}$ \\
\hline Alimento $^{3}$ & 3 & $180,00 * *$ & $1.544,53 * *$ & $12,04 * *$ & $61,00^{* *}$ \\
Ínstar $^{4}$ & 3 & $65,43 * *$ & $1.903,70 * *$ & $11,95 * *$ & $5,61 * *$ \\
Alimento x Ínstar & 9 & $16,36 * *$ & $325,65 * *$ & $3,38 * *$ & $0,91 * *$ \\
Resíduo & 238 & 0,81 & 14,33 & 0,15 & 0,09 \\
\hline C.V. $(\%)$ & & 23,98 & 30,20 & 29,80 & 15,13 \\
\hline
\end{tabular}

${ }^{1}$ Peso seco [mg].

${ }^{2} \mathrm{O}$ período de desenvolvimento foi considerado como sendo o número médio de dias em que o predador se alimentou.

${ }^{3}$ Alimento $=$ lagartas de $2^{\circ}, 3^{\circ}, 4^{\circ}$ e $5^{\circ}$ ínstares de A. argillacea .

${ }^{4}$ Alimento $=$ ninfas de $2^{\circ}, 3^{\circ}, 4^{\circ}$ e $5^{\circ}$ de $S$. cincticeps .

$* *$ Teste $\mathrm{F}[\mathrm{P} \leq 0,01]$.

favorecer, ao mesmo tempo, a redução dos níveis populacionais da praga, bem como a coevolução, isto é, a adaptação mútua e sobrevivência de ambas as espécies no agroecossistema.

O consumo total de alimento apresentado pelo $2^{\circ}$ ínstar do predador foi idêntico, quando teve como presa lagartas de $2^{\circ}, 3^{\circ}$ e $4^{\circ}$ ínstares. Durante o $3^{\circ}, 4^{\circ}$ e $5^{\circ}$ ínstares do predador, o consumo total foi maior ao se alimentarem de lagartas de $4^{\circ}$ e $5^{\circ}$ ínstares, quando comparado aos alimentos lagartas de $2^{\circ}$ e $3^{\circ}$ ínstares, nos quais a disponibilidade de alimento foi menor (Tabela 2). Assim, é provável que apenas lagartas de $5^{\circ}$ ínstar proporcionem ao predador uma quantidade de alimento que corresponde a sua capacidade máxima de consumo, a fim de atingir uma possível "saciação". Uma população de predador saciada por uma grande disponibilidade de presas terá maior chance de sobreviver e se reproduzir com sucesso no agroecossistema (Garcia 1991). Estes resultados têm importantes consequências para o desenvolvimento das ninfas de $S$. cincticeps, aumentando o período de desenvolvimento para aquelas que têm menor oferta de alimento, e diminuindo-o para aquelas onde a oferta de alimento é maior.

A sobrevivência do predador foi afetada pelo consumo de alimento, principalmente quando alimentou-se de lagartas de $2^{\circ}$ ínstar. O $5^{\circ}$ ínstar do predador, quando alimentado com lagartas de $2^{\circ}$ ínstar, isto é, sob escassez de alimento, teve uma sobrevivência de $28,6 \%$, enquanto nos demais alimentos a sobrevivência foi de $100,0 \%$. Isto demonstra que $S$. cincticeps pode desenvolver-se e sobreviver, mesmo em condições de escassez de alimento. Nos demais ínstares, quando tiveram como presa lagartas de $2^{\circ}, 3^{\circ}, 4^{\circ}$ e $5^{\circ}$ ínstares, a sobrevivência foi alta, variando de 50,0 a $100,0 \%$ (Tabela 2). Esses resultados concordam com os que Mukerji \& LeRoux (1969), que obtiveram, para ninfas de $P$. maculiventris, alimentadas com lagartas de Galleria mellonella (L.)(peso vivo $=3,7 \mathrm{mg}$ ), uma sobrevivência de $40,0 \%$ no $5^{\circ}$ ínstar, enquanto que para os demais ínstares e alimentos a sobrevivência foi alta. Eles constataram que a mortalidade das ninfas de $5^{\circ}$ ínstar ocorreu durante a ecdise. No presente estudo, a mortalidade das ninfas de $S$. cincticeps sempre ocorreu enquanto estas não 


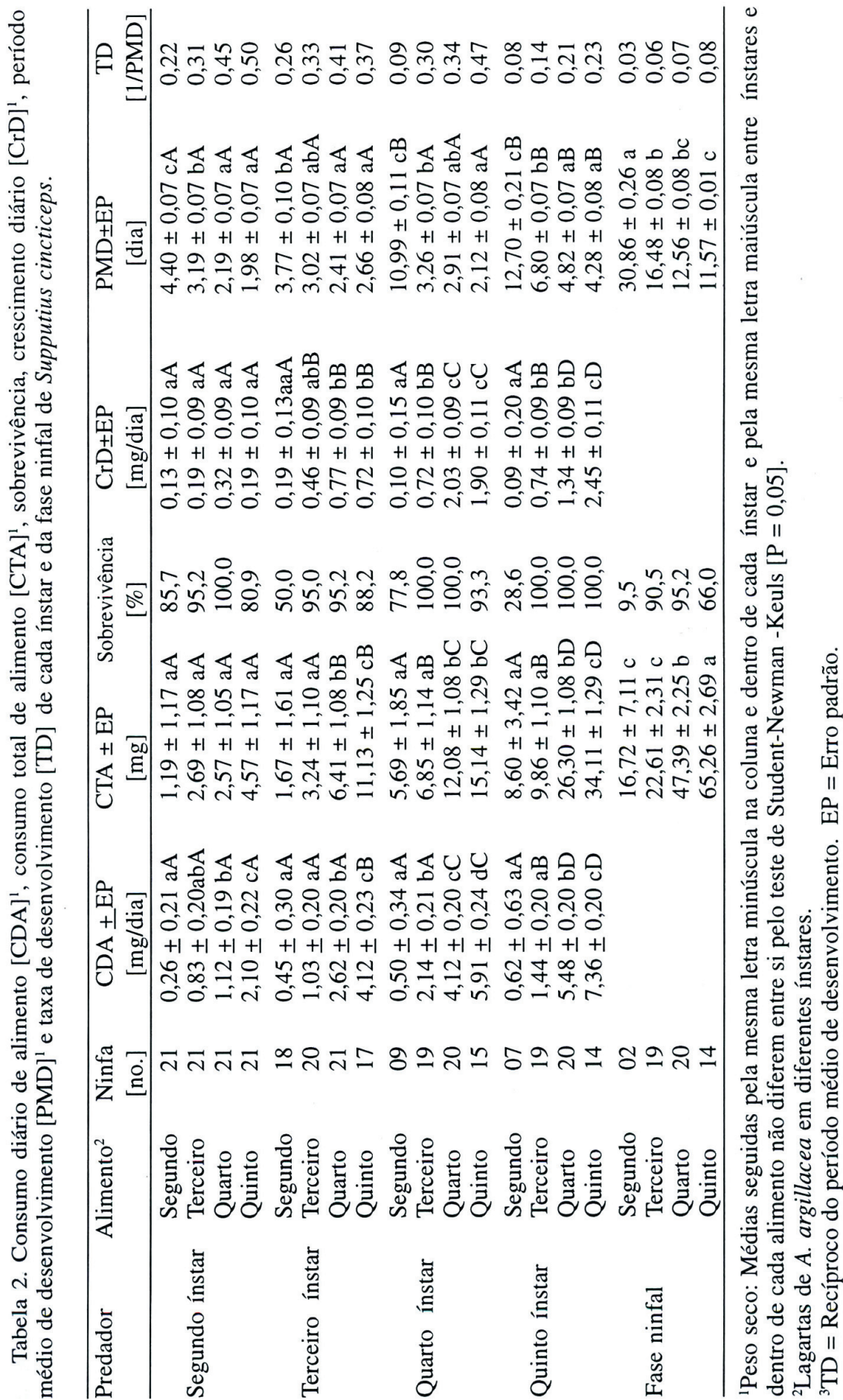


estavam trocando de tegumento, indicando que o alimento não foi suficiente para manter o metabolismo e o desenvolvimento até a fase adulta. Quando o predador alimentou-se de lagartas de $5^{\circ}$ ínstar, ocorreu uma sobrevivência de $80,9 \%$ de ninfas do $2^{\circ}$ ínstar, seguida de um aumento da sobrevivência, até atingir $100 \%$, no $5^{\circ}$ ínstar. Isto indica que a medida que o tamanho do predador aumenta, sua capacidade de consumir uma presa de tamanho significativamente maior do que o seu, também aumenta, e tem como conseqüência um incremento na sua sobrevivência.

$\mathrm{O}$ crescimento diário das ninfas de $2^{\circ}$ ínstar foi semelhante, independentemente da quantidade de alimento disponível. Para as ninfas de $3^{\circ}$ ínstar, a quantidade de alimento oferecida:lagartas de $2^{\circ}$ ínstar e em menor proporção: lagartas de $3^{\circ}$ ínstar, foi abaixo do necessário, para que ocorresse o crescimento ótimo do predador (Tabela 2), resultando possivelmente em adultos com peso do corpo menor que aqueles provenientes de ninfas que se alimentaram de lagartas de $4^{\circ}$ e $5^{\circ}$ ínstares, e principalmente de lagartas de $5^{\circ}$ ínstar. $\mathrm{O} 4^{\circ}$ ínstar do predador apresentou o maior crescimento diário, quando foi submetido a lagartas de $4^{\circ}$ e $5^{\circ}$ ínstares, enquanto que o $5^{\circ}$ ínstar teve o seu maior crescimento diário ao alimentar-se de lagartas de $5^{\circ}$ ínstar.

O número de dias gastos pelo predador na alimentação foi inversamente proporcional ao consumo de alimento em todos os instares. Resultados semelhantes foram obtidos para as espécies P. maculiventris (Mukerji \& LeRoux 1969) e P. nigrispinus (Santos et al. 1995), quando tiveram como presas lagartas de G. mellonella e A. argillacea, respectivamente. Portanto, é provável que o predador estenda o período de alimentação e reduza a taxa de desenvolvimento, quando ocorre uma baixa disponibilidade de alimento por um período prolongado. Por outro lado, com alimento em abundância, o predador reduz o período de alimentação e acelera o desenvolvimento (Tabela 2). Consequentemente, em condições de campo, o predador pode adaptar-se a uma situação de escassez de alimento, retomando o crescimento nor- mal à medida que a densidade populacional da presa aumentar, permitindo uma taxa de consumo satisfatória.

A análise de regressão da relação entre o consumo diário de alimento e o crescimento do $2^{\circ}$ instar do predador, mostrou que estas duas variáveis apresentam uma relação curvilínea de segundo grau (Fig. 1). O crescimento do $2^{\circ}$ instar do predador foi maior à medida que se aumentou o consumo diário de alimento. Entretanto, esta taxa decresceu quando as ninfas desse estádio alimentaramse de lagartas de $5^{\circ}$ ínstar. Provavelmente, isto ocorreu devido à presa (lagarta de $4^{\circ}$ instar) ser bem maior do que o predador, contribuindo para que o gasto de energia pelo predador para dominar a presa ser bem mais alto que a energia ganha pelo $S$. cincticeps, proveniente da presa. Para as ninfas do $3^{\circ}$ ao $5^{\circ}$ ínstar, a relação entre o consumo diário de alimento e crescimento foi linear (Fig. 1). Constatou-se que o crescimento do predador, depende da quantidade de alimento consumido, aumentando à medida que o consumo aumenta.

As baixas taxas de consumo apresentadas pelas ninfas de $S$. cincticeps, quando alimentaram-se de lagartas de $2^{\circ}$ e $3^{\circ}$ ínstares, limitaram bastante o crescimento das ninfas em todos os ínstares, quando comparadas com as taxas de consumo e o crescimento de ninfas que se alimentaram de lagartas de $4^{\circ}$ e $5^{\circ}$ ínstares (Tabela 2). É provável que os adultos do predador, provenientes das ninfas que tiveram como alimento lagartas de $2^{\circ}$ e $3^{\circ}$ ínstares, apresentem peso do corpo menor que aqueles alimentados de lagartas de $4^{\circ}$ e $5^{\circ}$ ínstares. Variações no tamanho de fêmeas de P. maculiventris provocam diferenças significativas na produção de ovos (Evans 1982). De acordo com estes resultados, o crescimento de ninfas de $S$. cincticeps é diretamente proporcional ao consumo de alimento, e que ninfas submetidas a escassez de alimento, provavelmente, dêem origem a adultos de menor tamanho e fêmeas com baixa taxa de reprodução.

Os estudos de regressão linear desenvolvidos para cada instar do predador, 

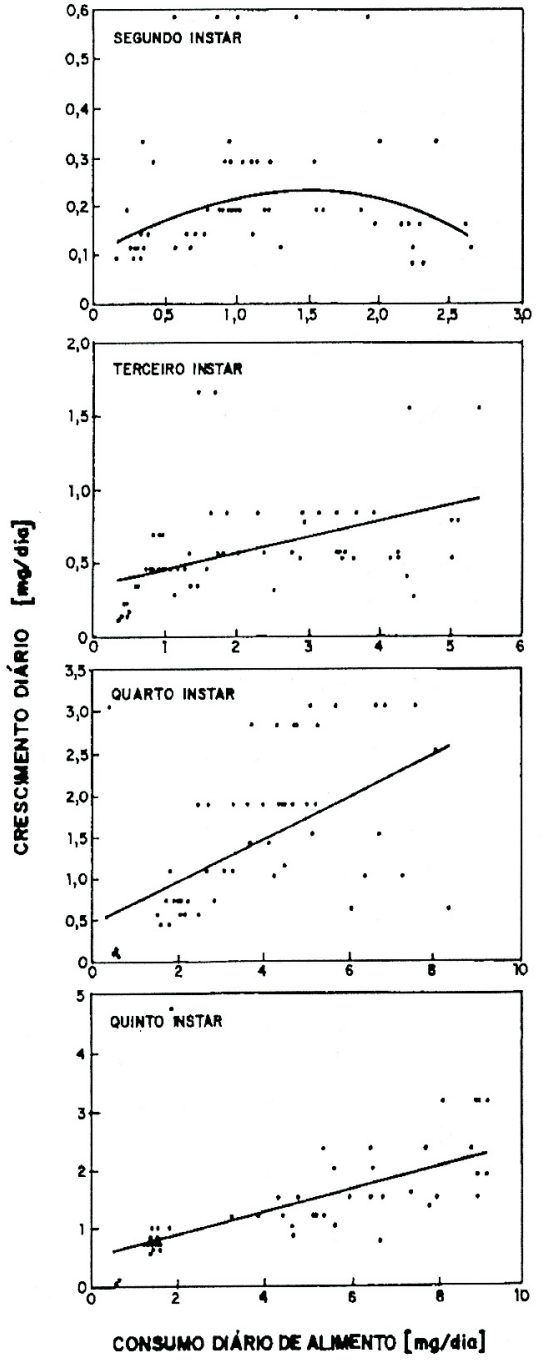

Figura 1. Relação entre consumo diário de alimento [mg de peso seco] e crescimento diário de ninfas de $2^{\circ}, 3^{\circ}, 4^{\circ}$ e $5^{\circ}$ instares de Supputius cincticeps, tendo como presa lagartas de $2^{\circ}, 3^{\circ}, 4^{\circ}$ e $5^{\circ}$ ínstares de Alabama argillace a $25^{\circ} \mathrm{C}, \mathrm{UR}$ de $70 \pm 10 \%$ e fotofase de 12 horas. 20 ínstar: Y=0,095958 $+0,181308 \mathrm{X}-0,062994 \mathrm{X}^{2}\left[\mathrm{~F}=15,92 ; \mathrm{R}^{2}=0,19\right.$; $\mathrm{P}<0,05], 3^{\circ}$ ínstar: $\mathrm{Y}=0,355383+0,104534 \mathrm{X}$ $\left[\mathrm{F}=15,14 ; \mathrm{R}^{2}=0,20 ; \mathrm{P}<0,05\right], 4^{\circ}$ ínstar: $\mathrm{Y}=0,477643+0,252351 \mathrm{X}\left[\mathrm{F}=25,63 ; \mathrm{R}^{2}=0,31\right.$; $\mathrm{P}<0,05], 5^{\circ}$ ínstar: $\mathrm{Y}=0,523537+0,193682 \mathrm{X}$ $\left[\mathrm{F}=34,00 ; \mathrm{R}^{2}=0,39 ; \mathrm{P}<0,05\right]$. entre o consumo diário de alimento e o recíproco do período de desenvolvimento, mostram que em cada um dos ínstares, o desenvolvimento das ninfas foi mais rápido nas dietas onde a taxa de consumo foi maior (Fig. 2).

Durante o $4^{\circ}$ e o $5^{\circ}$ ínstares de $S$. cincticeps (Fig. 2), os pontos referentes ao alimento lagartas de $2^{\circ}$ ínstar, estão localizados muito próximos do ponto de origem da ordenada e da abcissa, indicando que, nesses estádios, quando o consumo diminui, o tempo de desenvolvimento do $S$. cincticeps aumenta consideravelmente.

A inclinação da linha de regressão diminui do $2^{\circ}$ ao $5^{\circ}$ ínstar, êste com uma diminuição mais acentuada. Resultados semelhantes foram obtidos com o predador $P$. maculiventris (Mukerji \& LeRoux 1969) e com a aranha Linyphia triangularis Clerk (Turnbull 1962). A diminuição mais acentuada da inclinação da linha de regressão no $5^{\circ}$ ínstar significa que, nesse estádio, o predador precisa se alimentar por mais tempo, mesmo quando ocorre abundância de alimento, a fim de acumular reservas energéticas para a ecdise e conversão de parte dessa energia em tecidos definitivos do adulto, bem como em reservas energéticas para a fase adulta.

As linhas de regressão interceptam a abcissa à esquerda da origem (Fig. 2). Isso indica que o desenvolvimento do predador pode ocorrer mesmo na ausência de alimento. Constatou-se que $6,7 \%$ de ninfas de $S$. cincticeps completaram o desenvolvimento até o $3^{\circ}$ ínstar, na ausência de alimento, fenômeno anteriormente observado também com P. maculiventris (Mukerji \& LeRoux 1969). Esse fenômeno provavelmente decorre da obtenção da energia de ovos e água fornecida diariamente, ainda no $1^{\circ}$ ínstar.

As durações e as taxas de desenvolvimento de $S$. cincticeps da fase de ovo até a fase adulta, obtidas neste estudo, foram comparadas com as que Kasten Jr. \& Parra (1984) e Parra et al. (1984) obteveram para A. argillacea. Embora as cultivares de algodão, utilizadas como alimento para o 


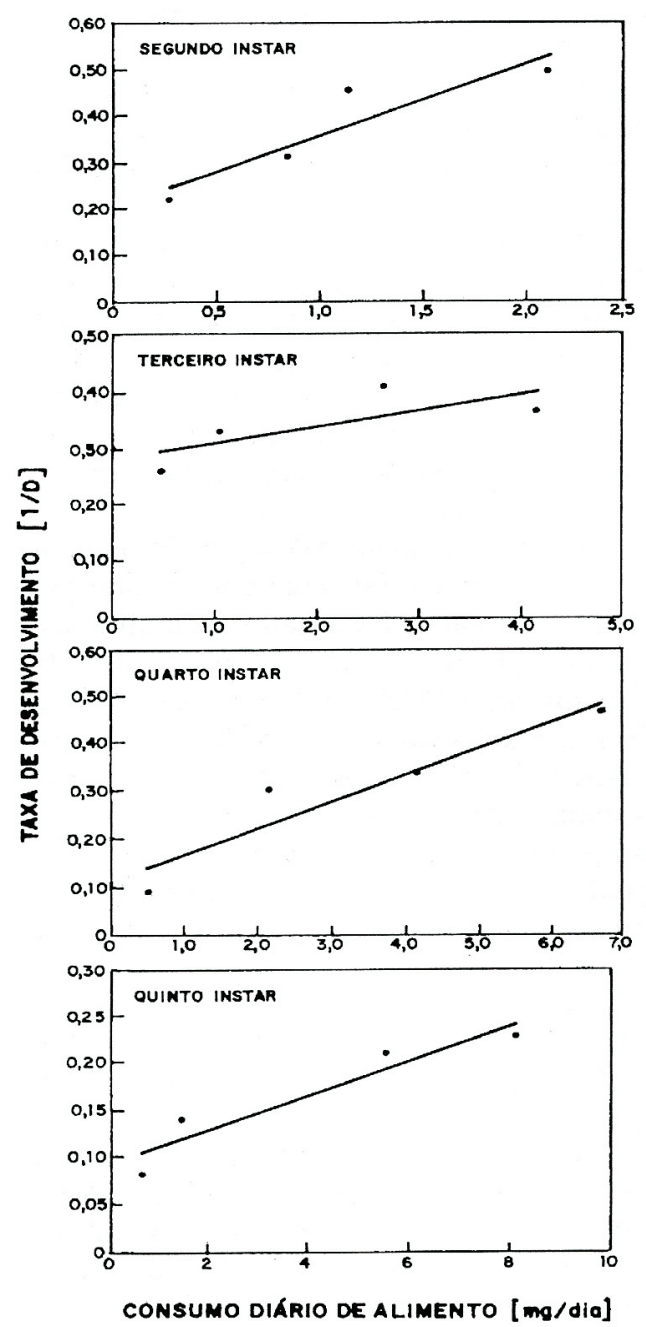

Figura 2. Relação entre consumo diário de alimento [mg de peso seco] e taxa de desenvolvimento de ninfas de $2^{\circ}, 3^{\circ}, 4^{\circ}$ e $5^{\circ}$ instares de Supputius cincticeps, tendo como presa lagartas de $2^{\circ}, 3^{\circ}, 4^{\circ}$ e $5^{\circ}$ ístares de Alabama argillacea a $25^{\circ} \mathrm{C}$, UR de $70 \pm 10 \%$ e fotofase de 12 horas. $2^{\circ}$ instar: $\mathrm{Y}=0,202640$ $+0,154663 \mathrm{X}\left[\mathrm{F}=11,56 ; \mathrm{R}^{2}=0,85 ; \mathrm{P}<0,05\right], 3^{\circ}$ ínstar: $\mathrm{Y}=0,282390+00,029251 \mathrm{X}[\mathrm{F}=6,76$; $\left.\mathrm{R}^{2}=0,57 ; \mathrm{P}<0,05\right], 4^{\circ}$ instar: $\mathrm{Y}=0,110963$ $+0,056555 \mathrm{X}\left[\mathrm{F}=17,96 ; \mathrm{R}^{2}=0,90 ; \mathrm{P}<0,05\right], 5^{\circ}$ Quinto ínstar: $\mathrm{Y}=0,092422+0,018598 \mathrm{X}$ $\left[\mathrm{F}=18,03 ; \mathrm{R}^{2}=0,90 ; \mathrm{P}<0,05\right] . \mathrm{D}=$ duração de desenvolvimento [dia]. curuquerê, não tenham sido as mesmas nos dois estudos, é possível que $S$. cincticeps, em condições de abundância de alimento, tenha uma velocidade de desenvolvimento próxima a de $A$. argillacea. Isto é importante, porque para um predador ser considerado eficiente, deve apresentar duração de desenvolvimento e tempo de maturação sexual iguais ou menores que os de sua presa.

\section{Agradecimentos}

Ao Conselho Nacional de Desenvolvimento Científico e Tecnológico - CNPq, pela concessão de auxílio financeiro para a realização da pesquisa.

\section{Literatura Citada}

Evans, E.W. 1982. Consequences of body sizes for fecundity in the predatory stink bug, Podisus maculiventris (Hemiptera:pentatomidae). Ann. Entomol. Soc. Am. 75:418-420.

Garcia, M.A. 1991. Ecologia nutricional de parasitóides e predadores terrestres, p.289-311. In: A.R. Panizzi \& J.R.P. Parra (eds.). Ecologia nutricional de insetos e suas implicações no manejo de pragas, São Paulo, Ed. Manole, 1991, 359 p.

Gravena, S. \& H.F. Cunha. 1991. Artrópodos predadores na cultura algodoeira: atividade sobre Alabama argillacea (Hueb.) com breves referências a Heliothis sp. (Lepidoptera:Noctuidae). Jaboticabal, FUNEP, Bol. Tec. 41p.

Grazia, J., M.C. Del Vecchio \& R. Hildebrand. 1985. Estudo das ninfas de heterópteros predadores. I. Podisus connexivus Bergroth, 1891 (Pentatomidae:Asopinae). An. Soc. Entomol. Brasil 14:303-314.

Hagen, K.S. 1987. Nutritional ecology of terrestrial insect predatorss, p. 533-577. In: F. Slansky Jr. \& J.G. Rodriguez (eds), 
Nutritional ecology of insects, mites, spiders, and related invertebrates, New York, Hohn Wiley \& Sons, 1016 p.

Kasten Jr., P. \& Parra, J.R. 1980. Bioecologia de Alabama argillacea. I. Biologia em diferentes temperaturas, na cultivar de algodoeiro IAC-17. Pesq. Agropec. Bras. 19:269-280.

Mukerji, M.K. \& E.J. Leroux. 1969. A quantitative study of food consumption and growth of Podisus maculiventris (Hemiptera:Pentatomidae). Can. Entomol. 101:387-403.

Newsom, L.D. \& C.E. Smith. 1949. Destruction of certain insect predators by application of insecticides to control cotton pests. J. Econ. Entomol. 42:904907.

Parra, J.P., S. Silveira Neto, P. Kasten Júnior, O. Brunini. 1984. Bio-ecologia de Alabama argillacea. II. Evolução populalacional em seis regiões do estado de São Paulo, com base em suas exigências térmicas. Pesq. Agropec. Bras. 19:417-421.

Price, P.W. 1975. Insect ecology. New York, John Wiley \& Sons, 514p.

Ramalho, F.S. 1994. Cotton pest management. Part 4. A brazilian perspective. Annu. Rev. Entomol. 39:563-578.

Santos, T.M., E.N. Silva \& F.S. Ramalho. 1995. Desenvolvimento ninfal de Podisus connexivus Bergroth (Hemiptera: Pentatomidae) alimentado com curuquerê-do-algodoeiro. Pesq. Agropec. Bras. 30:163-167.

SAS Institute. 1993. SAS User's guide: statistics. Cary, N.C., SAS Institute Inc. 589p.
Silva, E.N., T.M. Santos \& F.S. Ramalho. 1996. Desenvolvimento ninfal de Supputius cincticeps Stal (Hemiptera: Pentatomidae) alimentado com curuquerê-do-algodoeiro. An. Soc. Entomol. Brasil 25:103-108.

Turnbull, A.L. 1962. Quantitative studies of the food of Linyphia triangularis Clerck (Araneae:Linyphiidae). Can. Entomol. 94:1233-1249.

Zanuncio, J.C., J. Didonet, W.L. Garperazzo, G.P. Santos. 1993a. Desenvolvimento ninfal de Podisus connexivus Bergroth, 1891 (Hemiptera: Pentatomidae), alimentado com prépupas de Psorocampa denticulata (Lepidoptera:Notodontidae) e larvas de Tenebrio molitor (Coleoptera: Tenebrionidae). Rev. Bras. Entomol.37:523527.

Zanuncio, J.C., E.C. Nascimento, G.P. Santos, F.S. Araújo. 1991. Aspéctos biológicos do predador Podisus connexivus Bergroth, 1891 (Hemiptera: Pentatomidae). An. Soc. Entomol. Brasil 20:243-249.

Zanuncio, J.C., E.C. Nascimento, T.V. Zanuncio, A.P. Cruz. 1993b. Descrição das ninfas de Podisus sculptus Distant, 1889 (Hemiptera:Pentatomidae). Rev. Bras. Entomol. 37:403-408.

Zanuncio, T.V., L.A. Moreira, J.C. Zanuncio \& G.P. Santos. 1993c. Efeito da densidade ninfal na viabilidade e sobrevivência de Supputius cincticeps Stal, 1860 (Hemiptera:Pentatomidae) Tenebrio molitor (Coleoptera:Tenebrionidae). Rev. Bras. Entomol. 37:483487.

Recebido em 16/08/96. Aceito em 24/07/97. 